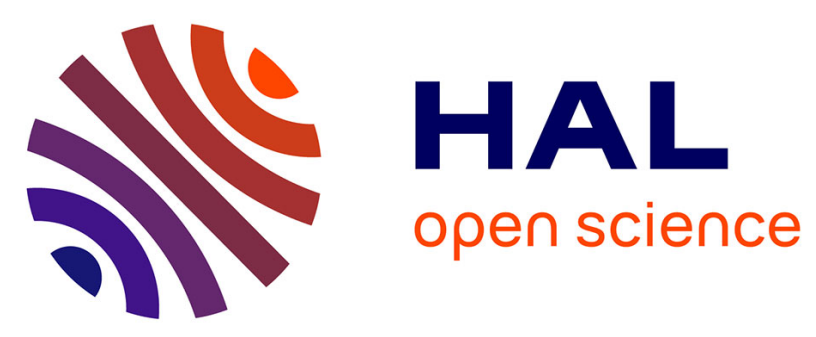

\title{
The effects of diet, mating duration, female to male ratios, and temperature on ovary activation, mating success, and fecundity of Aethina tumida
}

\author{
Lilia I. de Guzman, Thomas E. Rinderer, Amanda M. Frake
}

\section{To cite this version:}

Lilia I. de Guzman, Thomas E. Rinderer, Amanda M. Frake. The effects of diet, mating duration, female to male ratios, and temperature on ovary activation, mating success, and fecundity of Aethina tumida. Apidologie, 2015, 46 (3), pp.326-336. 10.1007/s13592-014-0325-y . hal-01284448

\author{
HAL Id: hal-01284448 \\ https://hal.science/hal-01284448
}

Submitted on 7 Mar 2016

HAL is a multi-disciplinary open access archive for the deposit and dissemination of scientific research documents, whether they are published or not. The documents may come from teaching and research institutions in France or abroad, or from public or private research centers.
L'archive ouverte pluridisciplinaire HAL, est destinée au dépôt et à la diffusion de documents scientifiques de niveau recherche, publiés ou non, émanant des établissements d'enseignement et de recherche français ou étrangers, des laboratoires publics ou privés. 


\title{
The effects of diet, mating duration, female to male ratios, and temperature on ovary activation, mating success, and fecundity of Aethina tumida
}

\author{
Lilia I. de Guzman, Thomas E. Rinderer, Amanda M. Frake \\ USDA-ARS, Honey Bee Breeding, Genetics and Physiology Laboratory, 1157 Ben Hur Road, Baton Rouge, LA 70820- \\ 5502, USA
}

Received 9 July 2014 - Revised 19 September 2014 - Accepted 1 October 2014

\begin{abstract}
The effects of natural diet (brood, pollen, honey, and their various combinations), mating duration (1 day versus 2 days), female $(\mathrm{F})$ to male $(\mathrm{M})$ ratio $(1 \mathrm{~F} / 1 \mathrm{M}, 2 \mathrm{~F} / 1 \mathrm{M}$, and $1 \mathrm{~F} / 2 \mathrm{M})$, and temperature (34 versus $27-$ $29^{\circ} \mathrm{C}$ ) on ovary activation, mating success, and fecundity of small hive beetles (SHBs) were studied. Our results indicated that regardless of mating duration, (1) a diet of brood, pollen, and honey presented together supported the highest fecundity; (2) intake of protein-rich diets encouraged ovary activation and egg-laying; and (3) diet of honey alone did not encourage ovary activation, mating success, and egg-laying at room temperature. Regardless of the number of males available for mating, egg-laying varied through time. Overall, females that were presented with two males for a 5-day mating period had higher fecundity than females provided with one male or three male partners. High temperature accelerated ovary activation and egg-laying regardless of female to male ratio during a $15-\mathrm{h}$ mating period. Knowledge of these factors that influence fecundity helps elucidate why SHBs are very successful pests of honey bees.
\end{abstract}

\section{Aethina tumida / fecundity / ovary activation / diet / mating duration / mating partner}

\section{INTRODUCTION}

Small hive beetles (Aethina tumida Murray, SHBs) are indigenous pests of two sub-Saharan African honey bees (Apis mellifera capensis and Apis mellifera scutellata) (Lundie 1940; Schmolke 1974, Neumann et al. 2013). SHBs cause little to no damage to African bees because they have well-developed removal behavior towards SHB eggs, larvae, and adults (Ellis et al. 2003, Ellis et al. 2004, Neumann et al. 2001b, Spiewok and Neumann 2006). In contrast, SHBs can kill colonies of

Corresponding author: L. Guzman, Lilia.DeGuzman@ARS.USDA.GOV Manuscript editor: Stan Schneider
European honey bees (EHBs) in the USA (Elzen et al. 1999, Connor 2011), Australia (Gillespie et al. 2003), and Canada (Clay 2006). This discrepancy may be due to their moderate responses to SHB-infested brood, which ranged from 10.6 to $77 \%$ (Ellis and Delaplane 2008) to as high as $85 \%$ (de Guzman et al. 2008).

Their ability to survive and reproduce, both of which are dependent upon temperature and diet, is also a major contributor to the invasion success of SHBs. Although some SHBs are confined to cracks and crevices around the hive by guard bees, their ability to induce bees to feed them trophallactically can increase their survival (Neumann et al. 2001b; Ellis et al. 2002b, Ellis and Hepburn 2006). In the laboratory, the longest average life spans of adult SHBs recorded were 6 months when fed with honey and pollen (Lundie 1940), 163 days on oranges (Arbogast 
et al. 2010), 167 days on honeycombs (Ellis et al. 2002a), and 354 days on honey solution (de Guzman et al. 2012) at room temperature. Lower average life spans were observed on standard pollen substitute patties (Bee-Pro ${ }^{\mathrm{TM}}$ ), which decreased as temperatures increased: 94 days at $28^{\circ} \mathrm{C}, 81$ days at $32{ }^{\circ} \mathrm{C}$, and 33 days at $35^{\circ} \mathrm{C}$ (Meikle and Patt 2011).

Fecundity of the SHB also varies. At $34^{\circ} \mathrm{C}$, the fecundity of individual females mated with one male and fed a mixture of pollen, honey bee pupae, and honey solution for 3 days was 58 eggs per day (de Guzman et al. 2012). Lower fecundities were recorded using multiple pairs kept at room temperature: 13 eggs per female per day (Schmolke 1974) and seven larvae per female per day (Ellis et al. 2002a) for beetles fed pollen and one egg per female per day (Ellis et al. 2002a) for mating pairs fed Kei apples. The lifetime fecundities of singlepair SHBs also differed depending on the diet and rearing conditions. Arbogast et al. (2010)) reported a median lifetime fecundity of 612 eggs on yeast-inoculated pollen dough (with $4 \%$ pollen) and 445 eggs on oranges at $28{ }^{\circ} \mathrm{C}$. Higher lifetime fecundities were recorded at higher temperature $\left(32{ }^{\circ} \mathrm{C}\right)$ by Meikle and Patt (2011): 1449 eggs on standard pollen substitute patty (Bee-Pro $\left.{ }^{\mathrm{TM}}\right), 919$ eggs on pollen and honey patty, and 1347 eggs when one honey bee pupa was added per $10 \mathrm{~g}$ of pollen and honey patty.

Although the effects of diet and temperature on SHB fecundity have been reported, all fecundity data are based on either individual females or group of females with continuous presence of males for mating and remating. Fecundity and oviposition patterns of females isolated from males after mating have not been reported. Further, the effects of diet, duration of mating, ratio of females to males, and temperature on mating success (indicated by the presence of spermatozoa), ovary activation, and subsequent egg-laying patterns in female SHBs have not been investigated. Therefore, these experiments were conducted to better understand the factors that influence the overall invasive success of SHBs.

\section{MATERIALS AND METHODS}

\subsection{Experiment 1. Effects of diet and duration of mating on ovary activation, mating success, and fecundity of females}

This study was conducted at room temperature (27$29{ }^{\circ} \mathrm{C}$ ). Male and female SHBs (average age $=3.8 \pm$ 0.2 days) used in this study were raised individually in microcentrifuge tubes as described by de Guzman and Frake (2007). Test beetles were maintained as virgins by keeping them individually in microcentrifuge tubes without food until use. Two mating groups of beetles were evaluated: (1) one virgin female held with one naïve (virgin or never been exposed to females) male for 1 day and (2) one virgin female held with one male for 2 days. For group 1, males were removed from the vials after 24 -h potential mating. These same males were re-used as mating partners for group 2 virgin females.

Mating groups (1 and 2) were placed in scintillation vials (volume $=20 \mathrm{~mL}$ ), the caps of which had two small holes (small enough to prevent SHB escape) for ventilation. Each group was allowed to mate inside the vials for the prescribed number of days (group $1=1$ day, group $2=2$ days), after which the males were removed. The vials were provided with one of the following natural diets: (a) brood (one honey bee pupa), (b) pollen $(0.20 \mathrm{~g})$, (c) honey solution (50 water/50 honey; $\sim 0.5 \mathrm{~mL}$ ), (d) brood and pollen, (e) pollen and honey, (f) honey and brood, and (g) brood, pollen, and honey. SHB does not reproduce when provided with empty brood comb, honeycomb, or no food (Schmolke 1974; Ellis et al. 2002a). Thus, honey solution served as a control in this study. For each food treatment, eight vials for each diet were prepared for a total of 112 vials for both mating groups. Each vial represented one replication. The same amount of fresh food was provided as needed.

To monitor egg-laying, the microscope slide technique (Keller 2002; Neumann et al. 2013) was initially used with modifications. In brief, a glass slide was cut into four sections to fit into the scintillation vials. Two cut sections were then taped together separated by half of a cover slip placed at both ends to create a small space for egg-laying. Each scintillation vial received one device as a place for egg-laying. In addition to the assigned diet, all vials were provided with one moist ( $\sim 1000 \mu \mathrm{L}$ of water) cotton ball for humidity. However, 
we observed that females laid more eggs in the cotton balls than in the slides. Also, a few of the SHBs had their legs entangled in the cotton balls; one had obvious leg injury. Hence, any female that died within the first week of observation were excluded from the experiment. To avoid further injury to beetles, cotton balls were replaced with sponges (length $=2.5 \mathrm{~cm}$, width= $1.3 \mathrm{~cm}$, thickness $=0.7 \mathrm{~cm}$ ), which the beetles readily used to lay eggs (one sponge moistened with $\sim 500 \mu \mathrm{L}$ water), to feed beetles (one sponge moistened with $\sim 500 \mu \mathrm{L}$ honey solution), and to provide humidity inside the vials. SHB fecundity in each vial was recorded by counting eggs in the sponges; 26 observations within a 33-day period.

At the end of the experiment, mating success was determined by dissecting spermatheca using a dissecting microscope. Each spermatheca was removed, placed in a drop of saline (Steiner et al. 1994) on a microscope slide, gently covered with a cover slip, and examined under a compound microscope for the presence of spermatozoa (see Figure 1a). The numbers of spermatozoa were not counted because SHB spermatozoa are long and frequently intertwined and clumps of spermatozoa are not readily separated. Activation of ovarioles was also noted; inactive ovaries had slender, translucent ovarioles while active ovaries had plump, opaque ovarioles (Figure 1b, c).

\subsection{Experiment 2. Effects of the number} of male partners on ovary activation, mating success, and fecundity of females

In this experiment, all 60 males (2-week old) were obtained from a cohort of mass-reared beetles (Neumann et al. 2001a; de Guzman and Frake 2007; Neumann et al. 2013). For the 30 females, 22 were from a cohort of individually reared beetles (4-7 days old) and eight were newly emerged. Except for the newly emerged females, all beetles were fed once with a small amount of pollen (about 1 tbsp), brood (about 10 pupae), and honey solution immediately after emergence. Thereafter, beetles were not provided food except water before being used. Mating containers were prepared as described in experiment 1 . Each scintillation vial contained one female, which was held with one, two, or three male partners ( $n=10$ vials per treatment). Each vial was provided with pollen $(0.2 \mathrm{~g})$, one sponge moistened with honey solution, and one honey bee pupa. Additional food was provided when necessary.
All vials were kept in an incubator at $34{ }^{\circ} \mathrm{C}$. After $15 \mathrm{~h}$ (overnight), each container was provided with one moist sponge for egg-laying and for additional humidity. Fecundity of females with the presence of males was observed daily for 5 days by examining sponges and inside walls of each container under a dissecting microscope. Eggs or newly hatched larvae were counted and removed. After 5 days, all males were removed and fecundity of females without males was then monitored everyday for 20 days and then every 3 days until the 44 th day. All sponges were replaced every 3 days. At the end of the experiment, reproductive tracts of females were dissected to confirm successful mating as described in experiment 1 .

\subsection{Experiment 3. Effects of male to female ratios and temperature on ovary activation and mating success of females held for $15 \mathrm{~h}$}

The lack of food may cause multiple pairs of SHBs not to lay eggs (Ellis et al. 2002a). In this study, mass-reared newly emerged females and males ( $\sim 100$ beetles) were also kept in a holding container without food except water at room temperature. After 3 days, 10 females were randomly selected and their reproductive tracts dissected to confirm that no mating had occurred inside the container. None of the females had spermatozoa in their spermathecae, and all had inactive ovaries. This cohort of beetles was used in this study since they had not mated. Beetles were sexed (Schmolke 1974; Neumann et al. 2013) and assigned to one of the following treatments: (a) one female held with one male, (b) two females held with one male, and (c) one female held with two males. For each treatment, 12 scintillation vials were prepared. Each vial was provided with pollen $(0.2 \mathrm{~g})$, one honey bee pupa, one sponge moistened with honey, and one sponge moistened with water to provide humidity. Six vials from each of the treatments were kept at room temperature $\left(27-29{ }^{\circ} \mathrm{C}\right)$, and six were placed in an incubator $\left(34{ }^{\circ} \mathrm{C}\right)$. Beetles were allowed to mate overnight $(15 \mathrm{~h})$. Thereafter, individual females were removed and placed in microcentrifuge vials for reproductive tract dissection as described in experiment 1. All sponges and inside walls of vials were also examined for the presence or absence of eggs. 

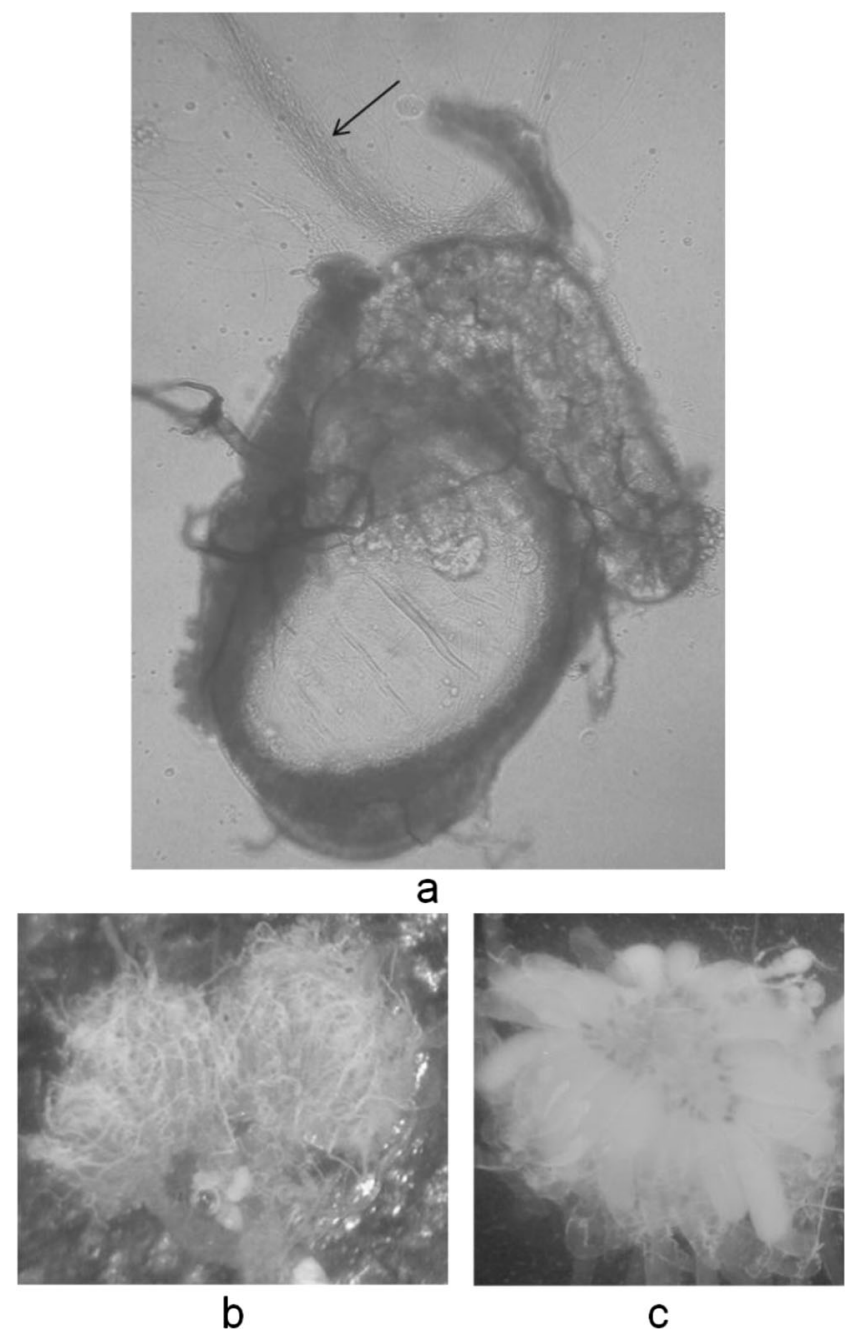

Figure 1. Spermatheca of a female small hive beetle. Arrow indicates sperm (a), two inactive ovaries (b), and one active ovary (c).

\subsection{Data analyses}

Before analysis, all data on the total number of eggs and the number of eggs laid per female per day were transformed with square-root transformation to better approximate normality. For experiment 1, a three-way mixed-model ANOVA with diet type, mating duration, and days of observation as the factors was performed to determine effects of these variables on fecundity. A significant three-way interaction was detected. Thus, a two-way analysis was performed for each mating duration group with diet type and days of observation as factors (PROC MIXED, SAS 2008). Once again, a significant two-way interaction was detected. Thus, means were compared with a one-way repeated measure ANOVA for each diet type with days of observation as the factor. For experiment 2, a repeated measure analysis was used to determine the effects of the number of male partners on the fecundity of females through time with number of males as the fixed effect and mating vials as the repeated subject. For experiment 3, a two-way ANOVA was used to determine the effects of temperature and the ratio of female and male on mating success. Where 
necessary, means were separated with a post hoc least-square means analysis.

\section{RESULTS}

\subsection{Experiment 1. Effects of diet} and duration of mating on ovary activation, mating success, and fecundity of females

Analysis revealed a significant interaction between the type of diet and days of observation on the fecundity of females held with one male for 1 day $(F=1.74 ; d f=138,1033$; $P<0.0001)$. Only those females fed pollen alone or any diet combined with pollen laid eggs and had active ovaries (Table I). Honeyfed females did not lay eggs and had inactive ovaries. Regardless of diet type, no spermatozoa were observed in the spermathecae of any of the females at the end of the experiment.

Similarly, fecundity was significantly affected by diet type and days of observations in females held with males for 2 days $(F=2.76$; $d f=132$, 968; $P<0.0001$ ) (Figure 2). However, none of the females fed exclusively with brood or honey laid eggs despite the presence of spermatozoa in the spermathecae of two females (brood-fed) and one female (honey-fed) (Table I). Although one honey-fed female had a few stored spermatozoa, all had inactive ovaries. It took a month before females fed brood and honey together started laying eggs. However, only two out of eight females laid eggs with a total of 119 eggs for 33 days. When brood or honey diets were combined with pollen, all of the females laid eggs as did the females fed pollen alone. However, females fed pollen alone (total $=828$ eggs) did not lay as many eggs as did the females fed pollen combined with brood or honey with a total of 2283 and 1845 eggs, respectively. The combination of brood, pollen, and honey supported the highest fecundity (up to 65 eggs per female per day) with a total of 6154 eggs over a period of 33 days. At the end of the experiment, all surviving females except those fed with honey had active ovaries, but not all of them had stored spermatozoa.

\subsection{Experiment 2. Effects of the number of male partners on ovary activation, mating success, and fecundity of females}

No interaction between the number of male partners and days of observation was detected for the fecundity of females $(F=1.15 ; d f=58,777$; $P=0.217)$. However, significant influences of observation days $(F=5.48 ; d f=29,777 ; P=0.01)$ (Figure 3$)$ and number of males $(F=11.59 ; d f=2$, 27; $P<0.0001)$ were observed for the fecundity of females. Regardless of the number of male partners, fecundity of females varied greatly during the 44 days of observation. Egg-laying started 1 day after the start of the experiment and increased dramatically on the second day. Thereafter, egglaying decreased gradually with a steep decline on the sixth day, the day after all males were removed from the females. Egg-laying remained low $(<20$ eggs per female per day) for about a week with the lowest egg production observed on the 12th day (0.3 egg per female). Fecundity increased dramatically on the 13th day, peaked on the 14th day, and decreased again with another steep decline on the 20th day (1.8 eggs per female) when the incubator malfunctioned. The use of another incubator coincided with another increase in egg production with another peak of egg production observed on the 22nd day (86 eggs per female). Thereafter, the oviposition rates of females declined to $<10$ eggs/female/day especially during the last three observation periods despite females having active ovaries and ample spermatozoa in their spermathecae.

Overall, females held with two males laid more eggs (41.9 \pm 4.1 eggs per female per day) than those females held with one $(26.1 \pm 2.9$ eggs per female per day) or three males $(31.9 \pm 3.5$ eggs per female per day) $(F=5.48 ; d f=2,27 ; P=0.01)$. There were two females (one mated with two and one mated with three males) that died during the 33-day observation period but laid a total of 1858 and 813 eggs, respectively, before death. Despite having no obvious abnormality, one female (mated with three males) laid one egg only over 44 days despite having a spermatheca filled with spermatozoa. Further, two females (mated with one male) laid a total of 748 and 1101 eggs (mated with two males) but did not have any 
Factors affecting ovary activation, mating success, and fecundity of SHB

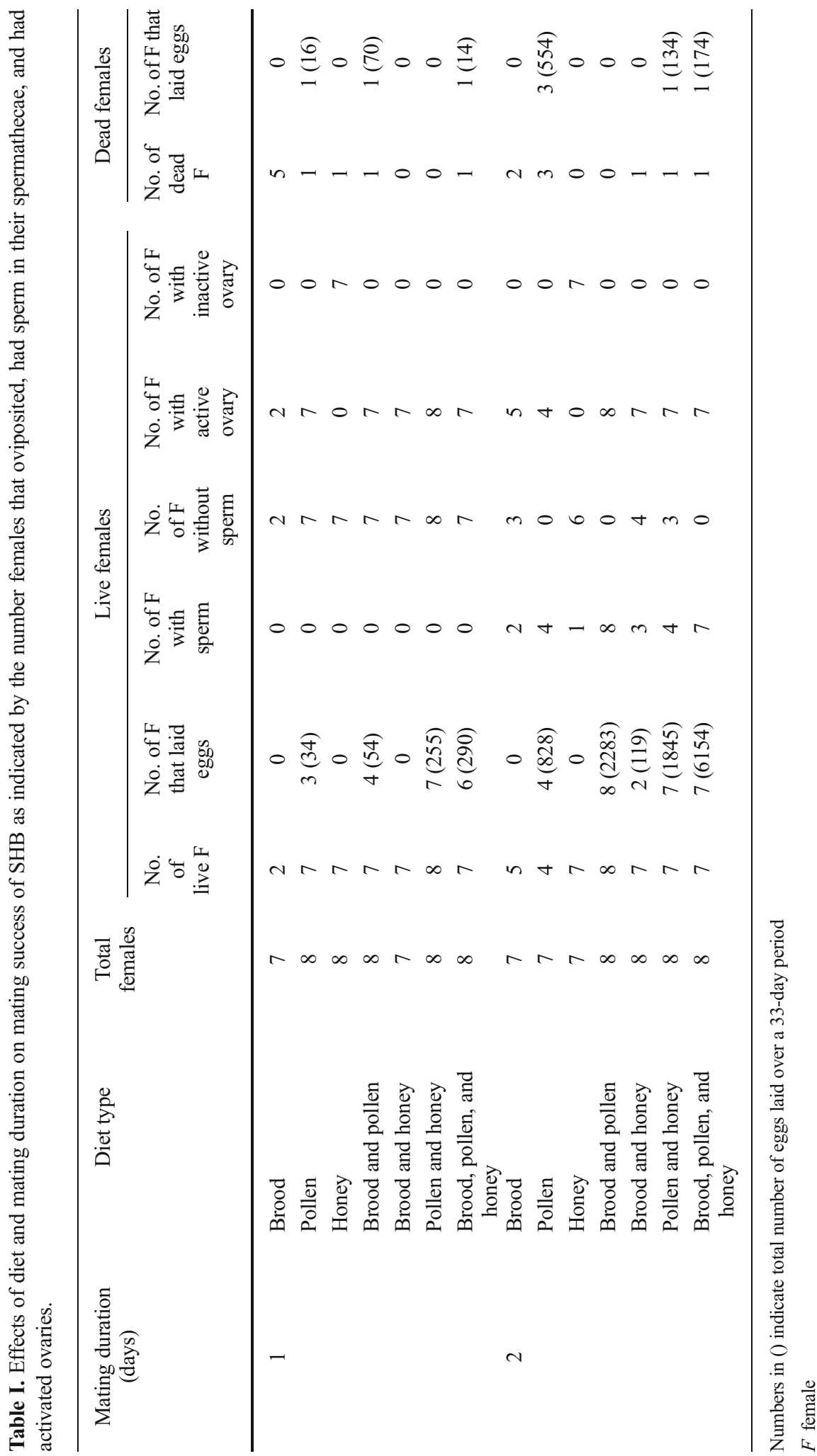




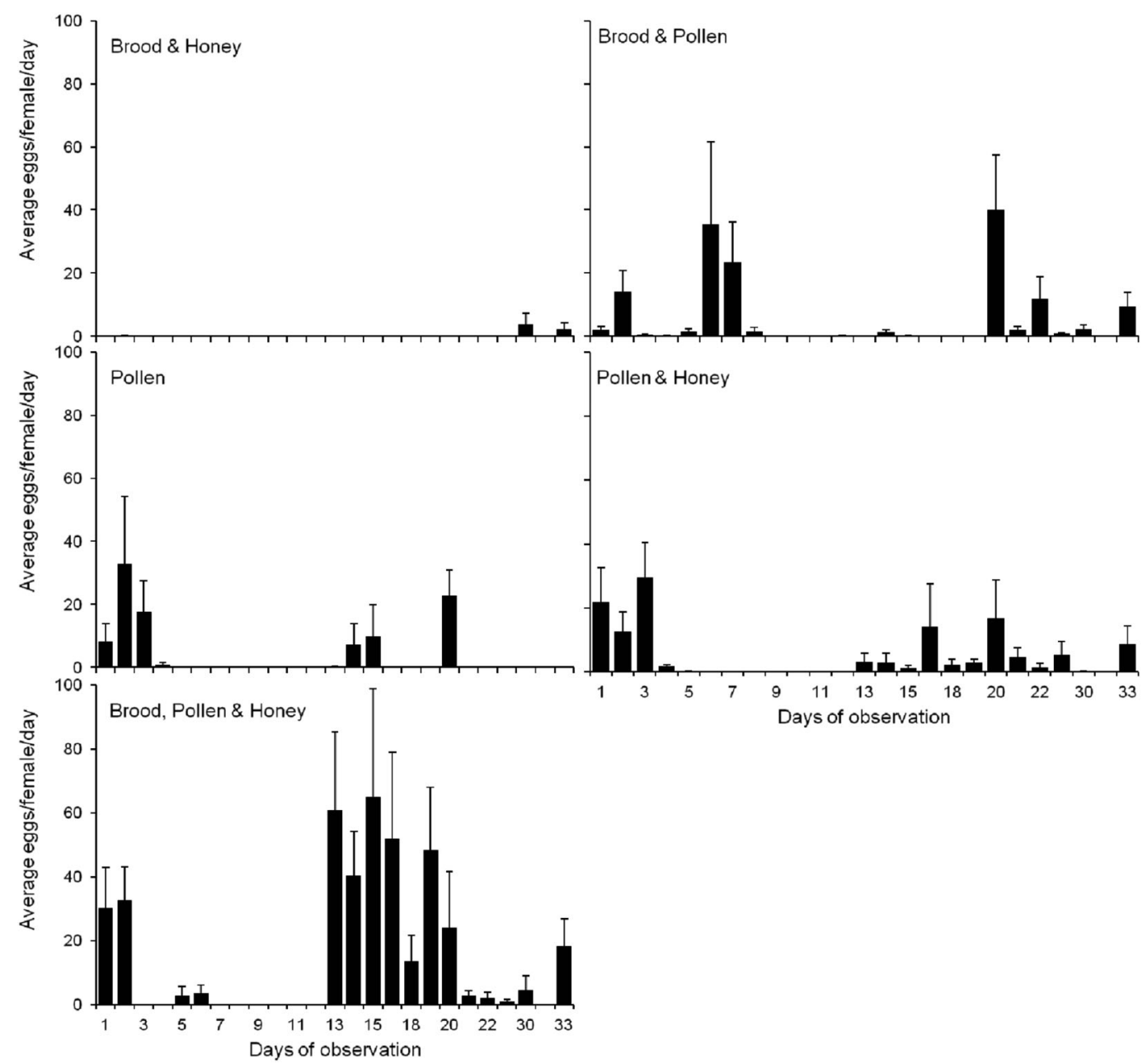

Figure 2. Average fecundity of female SHBs held with one male for 2 days and fed different natural diets at room temperature. Females exclusively fed brood and honey did not lay eggs.

spermatozoa in their spermathecae at the end of the experiment.

\subsection{Experiment 3. Effects of male to female} ratios and temperature on ovary activation and mating success of females held for $15 \mathrm{~h}$

No two-way interaction $(F=0.13 ; d f=2,30$; $P=0.877)$ or no female to male ratio $(F=0.13$; $d f=2,30 ; P=0.877$ ) effects were detected for the numbers of eggs laid and presence of activated ovaries (Table II). However, a significant effect of temperature on fecundity and ovary activation was observed $(F=18.28 ; d f=1,30 ; P=0.0002)$. Regardless of the female to male ratio, only those females that were kept inside the incubator laid eggs (1.4 \pm 0.4 eggs) after $15 \mathrm{~h}$. Regardless of the male/female ratio, all females kept with males in the incubator $\left(34{ }^{\circ} \mathrm{C}\right)$ had their ovaries activated while none to those females kept under room temperature $\left(27-29^{\circ} \mathrm{C}\right)$ had activated ovaries.

\section{DISCUSSION}

SHB produced more eggs when presented with a diet composed of brood, pollen, and honey 


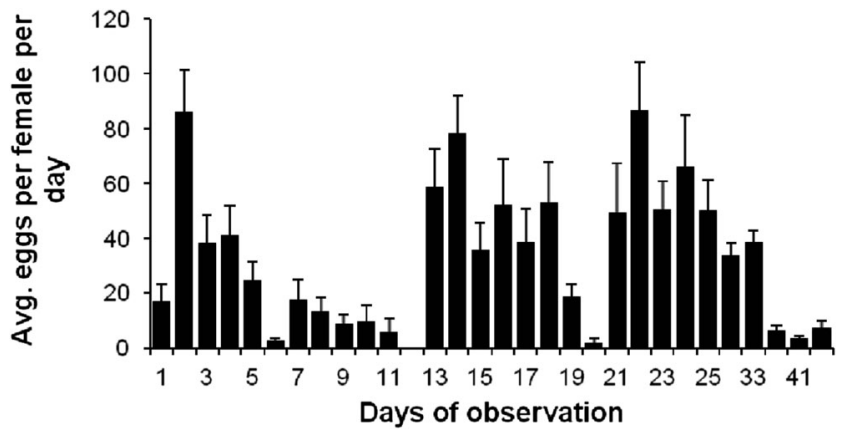

Figure 3. Average fecundity of female SHBs held with one to three males for 5 days at $34{ }^{\circ} \mathrm{C}$.

regardless of mating duration (Table I). This mirrors their habit of feeding on all food types available in a honey bee nest (Ellis et al. 2002a Arbogast et al. 2010). Although honey bees require only pollen as a protein source for optimum brood rearing (Haydak 1970; Herbert and Shimanuki 1978), their nest predator, the SHB, only optimizes egg-laying when the female adults have both pollen and honey bee brood as protein sources. A similar result was reported by Meikle and Patt (2011)) who reported lower lifetime fecundity (919 eggs) for those fed on pollen and honey patty than when one honey bee pupa was added per $10 \mathrm{~g}$ of pollen and honey patty (1347 eggs). However, for females mated for 2 days, we observed a much greater increase in fecundity when honey bee pupae were added to the diet of pollen and honey (from an average of 247 eggs to an average of 791 eggs per female for 33 days).
The diet we used had a higher proportion of protein from honey bee brood. Although honey bee pupae are also rich in protein (18.2\%) (Crane 1990), consumption of brood alone did not facilitate egg-laying as much as consumption of pollen alone or in combination with honey and/or brood. This observation on the reduced fecundity of females fed brood alone as compared to those fed a combination of pollen and honey contradicts the findings of Ellis et al. (2002a) who found higher fecundity in brood-fed beetles than those fed a mixture of pollen and honey. However, as the quality of pollen as a food source varies considerably (Pernal and Currie 2000), comparisons between the results of different experiments are difficult to interpret.

Diet affected ovary activation and mating success as indicated by the presence of spermatozoa in their spermathecae. Diet containing honey bee

Table II. Effects of temperature and ratio of female and male on egg-laying, mating (absence or presence of sperm), and ovary activation after $15 \mathrm{~h}$ of exposure.

\begin{tabular}{|c|c|c|c|c|c|c|}
\hline \multirow[t]{2}{*}{ Treatment type } & \multirow{2}{*}{$\begin{array}{c}\text { Total } \\
\text { females }\end{array}$} & \multirow{2}{*}{$\begin{array}{l}\text { Total no. } \\
\text { of eggs }\end{array}$} & \multirow{2}{*}{$\begin{array}{l}\text { No. of eggs } \\
\text { per female }\end{array}$} & \multirow{2}{*}{$\begin{array}{l}\text { Presence or } \\
\text { absence } \\
\text { of sperm }\end{array}$} & \multicolumn{2}{|c|}{ Ovary status } \\
\hline & & & & & Active $(\%)$ & Inactive $(\%)$ \\
\hline \multicolumn{7}{|c|}{ A. Incubator $\left(34{ }^{\circ} \mathrm{C}\right)$} \\
\hline 1 female and 1 male & 6 & 11 & $1.2 \pm 1.1$ & No & 100 & 0 \\
\hline 2 females and 1 male & 6 & 15 & $1.3 \pm 0.4$ & No & 100 & 0 \\
\hline 1 female and 2 males & 6 & 5 & $1.2 \pm 0.7$ & No & 100 & 0 \\
\hline \multicolumn{7}{|c|}{ B. Room temperature $\left(27-29^{\circ} \mathrm{C}\right)$} \\
\hline 1 female and 1 male & 6 & 0 & 0 & No & 0 & 100 \\
\hline 2 females and 1 male & 6 & 0 & 0 & No & 0 & 100 \\
\hline 1 female and 2 males & 6 & 0 & 0 & No & 0 & 100 \\
\hline
\end{tabular}


pupae supported ovary activation in all of the surviving brood-fed females. However, only $40 \%$ of them had stored spermatozoa. Honey is a carbohydrate that contains very little protein. As a result, none of the honey-fed females laid eggs although one female mated for 2 days had a few spermatozoa in her spermatheca after 33 days indicating successful mating. Also, a diet of honey alone did not enhance ovary activation. Our observations of ovary activation and spermathecal contents extend the observations of Ellis et al. (2002a)) who found minimal and no egg-laying by SHBs fed brood and honey, respectively. No reproduction in honey-fed beetles was also observed by de Guzman et al. (2012) despite their survival for an average of 354 days.

Overall, mating duration affected fecundity of SHBs. Allowing single pairs of SHBs to mate for 1 day only was not enough for females to receive enough spermatozoa to sustain oviposition for as long as those that were mated for 2 days. Also, the fecundity (number of egg per female per day) of females that were only able to mate for 2 days was equal or greater than that of females that were allowed to mate throughout the experimental period. Hence, mating periods of only 2 days can support egg-laying for a considerable time.

Although we varied the time permitted for mating under room temperature $\left(27-29^{\circ} \mathrm{C}\right)$, we did not determine how many times SHB females mated with males. Rather, we examined the contents of spermathecae to determine mating success. However, despite the presence of stored spermatozoa, not all females permitted to mate for 2 days laid eggs. Infertility has also been observed even in females held with males throughout their lifetime (Arbogast et al. 2010, Meikle and Patt 2011). This failure to lay eggs by females continuously exposed to males was presumed to be a result of mating failure (Arbogast et al. 2010). While some females were obviously unmated (no stored spermatozoa), two brood-fed, one brood- and honeyfed, and one honey-fed female were mated because of the presence of sperm in their spermathecae. It is unclear why these mated beetles did not lay eggs. Some of the females mated for 1 day that were fed pollen-rich diets (50-87\%) laid a few eggs. Thus, we presumed that these females were mated, but all had exhausted their spermatozoa on or before the 33-day observation period. Also, females held with males for 2 days laid more eggs. Most of these fecund females still had numerous spermatozoa in their spermathecae, but others had exhausted their supply of spermatozoa after laying eggs within the 33-day observation period. The absence of stored spermatozoa in females that laid eggs may be due to using all the spermatozoa available, which can probably be replenished through re-mating.

The number of mating partners also influenced fecundity. Females held with two mates had higher fecundity than females held with one or three mates, which may have been due to indiscriminate mating. It is possible that virgin females were unselective when presented with only two males. The similarity in the fecundity of females presented with one male or three male partners cannot be explained. Whether or not the most assertive males interfered with mate choice cannot be discerned from our available data.

Higher fecundity of females has been observed when multiple pairs of SHBs are held together. Overall, when individual females were given 5 days to mate either singly or multiply, fecundity of females was higher with more stored spermatozoa in their spermathecae after 44 days. De Guzman et al. (2012) estimated an average fecundity of 149 eggs per female per day using multiple pairs (10 pairs per container) as compared to 64 eggs per female per day for a single pair. Meikle and Patt (2011) obtained lower fecundity: 37 eggs per week per vial containing one mating pair, 250 eggs per week for those vials with three pairs, and 278 eggs per week with those containing five pairs. Also, our observations suggest that the SHB is similar to social insects in which multiple mating (polyandry) is a common phenomenon which promotes genetic diversity (Palmer and Oldroyd 2000).

None of our fecund females laid eggs continuously for 33 (Figure 2) or 44 (Figure 2) days despite the availability of food. This observation corroborates the findings of Arbogast et al. (2010)) and Meikle and Patt (2011) who showed periodic episodes of egg-laying by fecund females. We do not know what causes this periodicity. However, such periodicity has also been 
observed in locusts and cockroaches (reviewed by Bownes 1986).

Temperature is known to affect SHB development (de Guzman and Frake 2007) and reproduction (Meikle and Patt 2011). In this study, we found that high temperature also accelerated ovary activation. Within $15 \mathrm{~h}$ only, females held with males in the incubator all had activated ovaries, but only $61 \%(11 / 18)$ laid one to seven eggs. However, no sperm in their spermathecae was observed. This observation suggests that mating occurred but sperm was immediately exhausted within $15 \mathrm{~h}$. In contrast, all females held with males at room temperature had inactive ovaries and did not lay eggs. Our results may also suggest that high temperature facilitates maturation of ovarioles and mating. Egg-laying seemed to follow immediately after mating (in this case within $15 \mathrm{~h}$ ), but because of the short mating bouts, which probably did not allow repeated mating, females only received a few spermatozoa leading to the depletion of spermatozoa within a short period of time. This also suggests that repeated mating or re-mating is necessary for SHBs. Honey bees maintain an optimum temperature within the hive. Thus, SHB mating or re-mating and reproduction during winter may still occur, especially when protein-rich foods such as brood and pollen or pollen substitutes are available.

Our study showed that the SHB has a much higher egg-laying potential than previously reported. The highest numbers of eggs laid by one female was 3253 eggs (mated with one male for 5 days) and 1395 eggs (mated with one male for 2 days) over 44 and 33 days, respectively. It is possible that these beetles could have laid more eggs because they still had ample spermatozoa in their spermathecae. Although most females in this study still had stored spermatozoa after 33 or 44 days, periodic mating may be required to achieve lifetime egg-laying. Inside the colony, females will likely encounter males. Thus, the probability of re-mating to replenish depleted spermathecae is very high. This study demonstrates the high fecundity of female SHBs and, thus, reaffirms the seriousness of SHB infestations to honey bee colonies and some of the difficulties they present for effective controls. Their large reproductive potential in concert with episodic egg-laying, multiple mating, and re-mating all are challenges that need to be overcome to develop highly effective control strategies.

\section{ACKNOWLEDGMENTS}

We thank J.A. Stelzer, J. Wales, and G. Delatte for their technical assistance.

Les effets du régime alimentaire, de la durée de l'accouplement, du ratio femelle/mâle et de la température sur l'activation ovarienne, le succès de l'accouplement et la fécondité d' Aethina tumida

petit coléoptère des ruches / succès reproducteur / partenaire sexuel / ennemi de la ruche

Auswirkungen der Diät, Paarungsdauer, des Geschlechterverhältnisses und der Temperatur auf die Ovaraktivierung, den Parrungserfolg und die Fekundität von Aethina tumida

Aethina tumida / Fekundität / Ovaraktivierung / Paarungsdauer / Paarungspartner

\section{REFERENCES}

Arbogast, R.T., Torto, B., Teal, P.E.A. (2010) Potential for population growth of the small hive beetle Aethina tumida (Coleoptera: Nitidulidae) on diets of pollen dough and oranges. Fla. Entomol. 93, 224-230

Bownes, M. (1986) Expression of the genes coding for vitellogenin (yolk protein). Ann. Rev. Entomol. 31, 507-531

Clay, H (2006) Small hive beetle in Canada. Hivelights 19 , 14-16

Connor, L. (2011) Wipe out! The big island in crisis. Bee Cult. 139, 56-60

Crane, E. (1990). Bees and beekeeping: Science, Practice and World Resources. Cornstock Publ., Ithaca, NY., USA

de Guzman, L.I., Frake, A.M. (2007) Temperature affects Aethina tumida (Coleoptera: Nitidulidae) development. J. Apic. Res. 46, 88-93

de Guzman, L.I., Frake, A.M., Rinderer, T.E. (2008) Detection and removal of brood infested with eggs and larvae of small hive beetles (Aethina tumida Murray) by Russian and Italian honey bees. J. Apic. Res. 47, 216-221

de Guzman, L.I., Frake, A.M., Rinderer, T.E. (2012) Marking small hive beetles with thoracic notching: Effects 
on longevity, flight ability and fecundity. Apidologie 43, 425-431

Ellis, J.D., Neumann, P., Hepburn, H.R., Elzen, P.J. (2002a) Longevity and reproductive success of Aethina tumida (Coleoptera: Nitidulidae) fed different natural diets. J. Econ. Entomol. 95, 902-907

Ellis, J., Pirk, C., Hepburn, H., Kastberger, G., Elzen, P. (2002b) Small hive beetles survive in honeybee prisons by behavioural mimicry. Naturwissenschaften 89, 326-328

Ellis, J.D., Richard, C.S., Hepburn, H.R., Elzen, P.J. (2003) Oviposition by small hive beetles elicits hygienic responses from Cape honey bees. Naturwissenschaften 90, 532-535

Ellis, J.D., Delaplane, K.S., Richard, C.S., Hepburn, H.R., Berry, J.A., Elzen, P.J. (2004) Hygienic behaviour of Cape and European Apis mellifera (Hymenoptera: Apidae) toward Aethina tumida (Coleoptera: Nitidulidae) eggs oviposited in sealed bee brood. Ann. Entomol. Soc. Amer. 97, 860-864

Ellis, J.D., Hepburn, H.R. (2006) An ecological digest of the small hive beetle (Aethina tumida), a symbiont in honey bee colonies (Apis mellifera). Insectes Soc. 53, 8-19

Ellis, J.D., Delaplane, K.S. (2008) Small hive beetle (Aethina tumida) oviposition behaviour in sealed brood cells with notes on the removal of the cell contents by European honey bees (Apis mellifera). J. Apic. Res. 47, 210-215

Gillespie, P., Staples, J., King, C., Fletcher, M.J., Dominiak, B.C. (2003) Small hive beetle, Aethina tumida (Murray) (Coleoptera: Nitidulidae) in New South Wales. General and Applied Entomology 32: 5-7

Haydak, M.H. (1970) Honey bee nutrition. Ann. Rev. Entomol. 15, 143-156

Herbert, E.W., Shimanuki, H. (1978) Chemical composition and nutritive value of bee-collected and bee-stored pollen. Apidologie 9, 33-40

Keller, J.J. (2002) Testing effects of alternative diets on reproduction rates of the small hive beetle, Aethina tumida. Ms Thesis North Carolina State University. $55 \mathrm{pp}$
Lundie, A.E. (1940) The small hive beetle. Aethina tumida. Science Bulletin, Department of Agriculture and Forestry, Union of South Africa. 220

Meikle, W.G., Patt, J.M. (2011) The effects of temperature, diet, and other factors on development, survivorship, and oviposition of Aethina tumida (Coleoptera: Nitidulidae). J. Econ. Entomol. 104, 753-763

Neumann, P., Pirk, C.W.W., Hepburn, H.R., Elzen, P.J., Baxter, J.R. (2001a) Laboratory rearing of small hive beetle, Aethina tumida (Coleoptera: Nitidulidae). J. Apic. Res. 40, 111-112

Neumann, P., Pirk, C., Hepburn, H., Solbrig, A., Ratnieks, F., Elzen, P., Baxter, J. (2001b) Social encapsulation of beetle parasites by Cape honeybee colonies (Apis mellifera capensis Esch.). Naturwissenschaften $\mathbf{8 8}$, 214-216

Neumann, P., Evans, J.D., Pettis, J.S., Pirk, C.W.W., Schaefer, M.O., Tanner, G., Ellis, J.D. (2013) Standard methods for small hive beetle research. J. Apic. Res. 52, no. 4, DOI: 10.3896/IBRA.1.52.4.19

Palmer, A., Oldroyd, B.P. (2000) Evolution of multiple mating in the genus Apis. Apidologie 31, 235-248

Pernal, S.F., Currie, R.W. (2000) Pollen quality of fresh and 1 -year-old single pollen diets for worker honey bees. Apidologie 31, 387-409

SAS Institute, Inc. (2008) SAS User's Guide, Version 8.2, SAS Institute, Cary, NC

Schmolke, M.D. (1974) A Study of Aethina tumida: The Small Hive Beetle. University of Rhodesia (Zimbabwe), Certificate in Field Ecology Project Report, Salisbury (Harare). $178 \mathrm{pp}$

Spiewok, S., Neumann, P. (2006) The impact of recent queenloss and colony phenotype on the removal of small hive beetle (Aethina tumida Murray) eggs and larvae by African honey bee colonies (Apis mellifera capensis Esch.). J. Insect Behav 19, 601-611

Steiner, J., Dittmann, F., Rosenkranz, P., Engels, W. (1994) The first gonocycle of the parasitic mite (Varroa jacobsoni) in relation to preimaginal development of its host, the honey bee). Invertebr. Rep. Develop. 25, 175-183 